\title{
Monte Carlo Computation of Dose-Volume Histograms in Structures at Risk of an Eye Irradiated with Heterogeneous Ruthenium-106 Plaques
}

\author{
Francisco J. Zaragoza ${ }^{a}$ Marion Eichmann ${ }^{b}$ Dirk Flühs ${ }^{c}$ Beate Timmermann ${ }^{d-h}$ \\ Lorenzo Brualla ${ }^{d-f}$ \\ ${ }^{a}$ Faculty of Medicine, University of Duisburg-Essen, Essen, Germany; ${ }^{b}$ Fakultät Physik, Technische Universität \\ Dortmund, Dortmund, Germany; ${ }^{C}$ NCTeam, Strahlenklinik, Universitätsklinikum Essen, Essen, Germany; ${ }^{d}$ West \\ German Proton Therapy Center Essen (WPE), Essen, Germany; ${ }^{~}$ West German Cancer Center (WTZ), Essen, Germany;

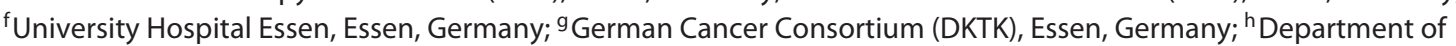 \\ Particle Therapy, University Hospital Essen, Essen, Germany
}

\section{Keywords}

Monte Carlo · Brachytherapy · PENELOPE · Ruthenium • Eye plaques · $\beta$-Emitter · Treatment planning - Dosimetry · Dose-volume histogram

\footnotetext{
Abstract

Background/Aims: The aim of this work is to compare Monte Carlo simulated absorbed dose distributions obtained from ${ }^{106} \mathrm{Ru}$ eye plaques, whose heterogeneous emitter distribution is known, with the common homogeneous approximation. The effect of these heterogeneities on segmented structures at risk is analyzed using an anthropomorphic phantom. Methods: The generic CCA and CCB, with a homogeneous emitter map, and the specific CCA1364 and CCB1256 ${ }^{106} \mathrm{Ru}$ eye plaques are modeled with the Monte Carlo code PENELOPE. To compare the effect of the heterogeneities in the segmented volumes, cumulative dose-volume histograms are calculated for different rotations of the aforementioned plaques. Results: For the cornea, the CCA with the equatorial placement yields the lowest absorbed dose rate while for the
}

CCA1364 in the same placement the absorbed dose rate is $33 \%$ higher. The CCB1256 with the hot spot oriented towards the cornea yields the maximum dose rate per unit of activity while it is 44\% lower for the CCB. Conclusions: Dose calculations based on a homogeneous distribution of the emitter substance yield the lowest absorbed dose in the analyzed structures for all plaque placements. Treatment planning based on such calculations may result in an overdose of the structures at risk.

๑) 2020 S. Karger AG, Basel

\section{Introduction}

${ }^{106} \mathrm{Ru}$ eye plaques are used to treat malignant intraocular tumors, such as uveal melanomas and retinoblastomas [1-12]. Although ${ }^{106} \mathrm{Ru}$ eye plaques have been widely studied using different methods [13-20], Monte Carlo simulations are considered the most accurate approach to compute absorbed dose distributions in radiotherapy when small fields are involved karger@karger.com

(c) 2020 S. Karger AG, Basel

www.karger.com/oop

Karger ${ }^{\prime}=$
Lorenzo Brualla

West German Proton Therapy Center Essen (WPE)

Hufelandstrasse 55

DE-45147 Essen (Germany)

lorenzo.brualla@uni-due.de 
[21-24]. The accuracy of the method is limited only by the underlying cross-section models, the radiation transport algorithms, and the reached statistical uncertainty.

There is, in general, a lack of accurate knowledge on the absorbed dose distribution in the eye, especially in the structures at risk, and its effects on clinical outcome [12, 25-27]. The first works that used simulations for computing the dose distribution considered the eye as a water sphere and the radioactive substance homogeneously distributed in the plaque. Using Monte Carlo methods, Brualla et al. [28] determined the absorbed dose distribution inside a computerized tomography (CT) of an eye, while considering the radioactive substance to be homogeneously distributed in the plaque. In a posterior work, Zaragoza et al. [29] computed the absorbed dose distribution in a water phantom employing the actual distribution of the emitter substance from 2 specific plaques, namely CCA1364 and CCB1256. More recently, Zaragoza et al. [30] simulated the treatment of uveal melanomas using CT of an eye and plaques CCA1364 and CCB1256. The available treatment planning system for eye plaques, called Plaque Simulator [15], uses approximate analytical methods for computing the absorbed dose distribution in a homogeneous water phantom, and, until recently, it considered the emitter distribution on the plaque to be homogeneous. The most recent version of this code uses the sparse information on the inhomogeneity of the plaque provided in the certificate for computing the dose distribution. It is clear that a dose computation, in which a detailed emitter map of the plaque is employed, together with a Monte Carlo simulation of the radiation transport in a CT of the patient, in which the actual heterogeneous mass density is considered, will yield a more accurate distribution than that obtained with the EYEPLAN code. This is particularly relevant for the computation of the absorbed dose outside the target volume, with emphasis on the structures at risk. European and many national laws currently require the appropriate computation of the dose delivered to non-target volumes (see for example article 56.1 from the Council Directive [31]).

The present study aimed to elucidate the effect of heterogeneous emitter distributions on the structures at risk using the same eye model and plaques employed in our previous research. The relative position of the eye plaques and the heterogeneities of the emitter substance are taken into account to assess the effect of the latter on the structures analyzed.

\section{Materials and Methods}

\section{Geometry of the Plaques}

Plaques CCA1364 and CCB1256 from the manufacturer BEBIG (Eckert \& Ziegler BEBIG, Berlin, Germany) are considered in this work. Both plaques consist of a spherical truncated cap of 12.0 $\mathrm{mm}$ (inner radius) along their symmetry axis. The outer diameter of the cap across the rim amounts to $15.5 \mathrm{~mm}$ for the CCA1364 and $20.2 \mathrm{~mm}$ for the CCB1256. The plaques are made of 3 silver layers of $0.1,0.2$, and $0.7 \mathrm{~mm}$ of thickness from the inner to the outer surface. The active layer, where the radioactive substance is electrolytically deposited in its inner surface, corresponds to the middle layer. This layer is encapsulated between the inner (or window) layer and the outer (or shielding) layer and does not cover the whole surface, falling short of the rim by $0.7 \mathrm{~mm}$. The emitter substance distribution, which was measured using a device specifically developed at the Technical University of Dortmund [32], is heterogeneous in both plaques.

The plaques are modeled using the constructive quadric geometry package provided by the general-purpose Monte Carlo radiation transport simulation code PENELOPE $[33,34]$. The activities of the plaques, which are reported on their respective certificate, are 11.6 MBq for the CCA1364 and 27.3 MBq for the CCB1256, while the nominal activities quoted by the manufacturer are 13.7 $\mathrm{MBq}$ for the generic CCA and $25.9 \mathrm{MBq}$ for the generic CCB. For the actual plaques (CCA1364 and CCB1256), the activities reported in their respective certificates, corrected by the date when they were measured at Dortmund, were used. For the generic CCA and CCB plaques, the nominal activities were employed. The accuracy of the simulation system was previously validated by comparison of the simulated results in a water phantom with experimental data $[19,35]$.

\section{Simulation Codes}

The radioactive isotope of ${ }^{106} \mathrm{Ru}$ decays into ${ }^{106} \mathrm{Rh}$, producing a $\beta$-spectrum of a maximum energy of $39 \mathrm{keV}$ and a half-life of 368 days. Subsequently, ${ }^{106} \mathrm{Rh}$ disintegrates into stable ${ }^{106} \mathrm{Pd}$, producing a $\beta$-spectrum used for therapeutic purposes, characterized by a maximum energy of $3.540 \mathrm{MeV}$ and a half-life of $29.8 \mathrm{~s}$.

Simulations were run with the PENELOPE (2008) code [33] using penEasy (2010-09-07) [36] as the main steering program. Since the employed version of penEasy/PENELOPE is not prepared to simulate $\beta$-decay spectra and heterogeneous radiation sources, 2 modifications are needed. An adapted version of the EFFY code [37], which uses the Fermi theory to describe the $\beta$-decay, was incorporated into the penEasy code to simulate the decay of ${ }^{106} \mathrm{Rh}$ into ${ }^{106} \mathrm{Pd}$ through the 5 disintegrations with the highest yields, i.e., $3.540 \mathrm{MeV}$ (78.6\%), $3.050 \mathrm{MeV}$ (8.1\%), 2.410 $\mathrm{MeV}$ (10.0\%), 2.000 MeV (1.77\%), and $1.539 \mathrm{MeV}(0.46 \%)$. The second modification is aimed at using the probability distributions of the experimental heterogeneous emitter maps to sample primary electrons over the plaque surface.

\section{Voxelized Geometry}

The size of an emmetropic eyeball does not differ from one individual to another [38]. Therefore, the conclusions derived from the CT employed are general enough. This CT was also used in previous works [30,39-41]. The CT scan has $256 \times 256 \times 59$ voxels of $0.03125 \times 0.03125 \times 0.1 \mathrm{~cm}^{3}$. Hounsfield units are converted into mass density values using the calibration curve of the CT scan- 


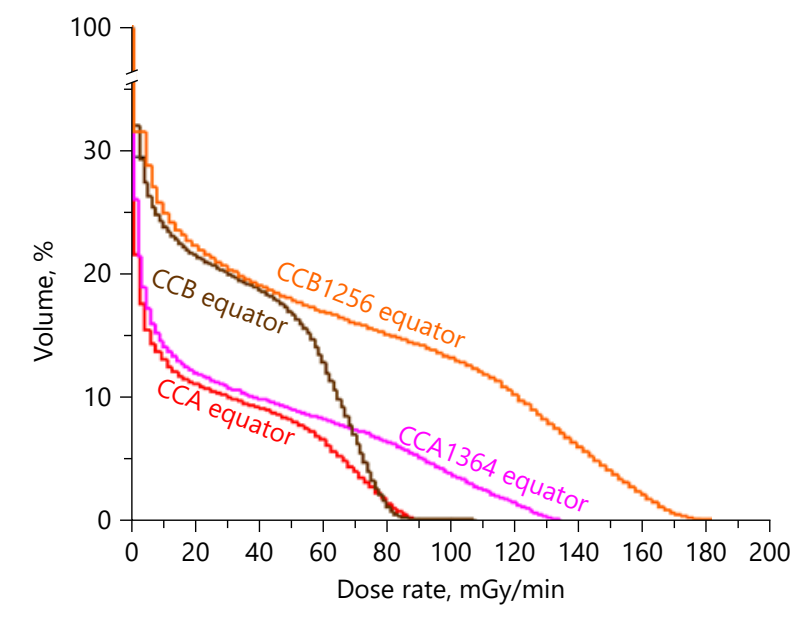

Fig. 1. Dose-volume histograms for the sclera corresponding to plaques in an equatorial placement.

ner. Three materials are considered: water, air, and bone. A distinctive feature of penEasy that allows overlapping quadric surfaces in a voxelized geometry is used to simulate the geometry of the plaques embedded in the voxelized human phantom.

\section{Placement of the Plaques}

Eye plaques are placed with its symmetry axis coplanar with the axial plane of the CT scan where the eyeball shows its largest diameter, which corresponds to slice 21 of the CT scan.

For the simulations of the CCA (generic plaque with a homogenous distribution of the emitter substance) and the CCA1364 (actual heterogeneous plaque) plaques, 3 different locations with respect to the equatorial plane of the eyeball previously defined are considered. These locations are called anterior, equatorial, and posterior. The anterior location is set $15^{\circ}$ above the equatorial plane of the eye, that is $30^{\circ}$ above the horizontal axis of the CT scan. On the equatorial location, the symmetry axis of the plaque coincides with the equatorial plane of the eye, that is $15^{\circ}$ above the horizontal axis of the tomography scan. The posterior location is set $15^{\circ}$ below the equatorial plane of the eyeball, that is $30^{\circ}$ below the horizontal axis of the tomography scan. For the simulations of the CCB (homogeneous) and the CCB1256 (heterogeneous) eye plaques, only the equatorial location is considered.

\section{Orientation of the Plaques}

The influence of the heterogeneities on the emission map of the plaques is studied. Rotations around the symmetry axis of the plaques allow to analyze the effect of the heterogeneities. Despite the heterogeneity of the CCA1364 plaque, it does not show a well-defined hot spot. Therefore, rotations are not applied to this plaque. Conversely, the CCB1256 has a hot spot whose activity amounts to $25 \%$ above the average of the plaque. The effect of the relative position of the hot spot with respect to the segmented structures is analyzed by 3 rotations. In the original rotation, the hot spot is located $42^{\circ}$ below the axial plane corresponding to slice 21 of the CT scan. In the proximal rotation, the

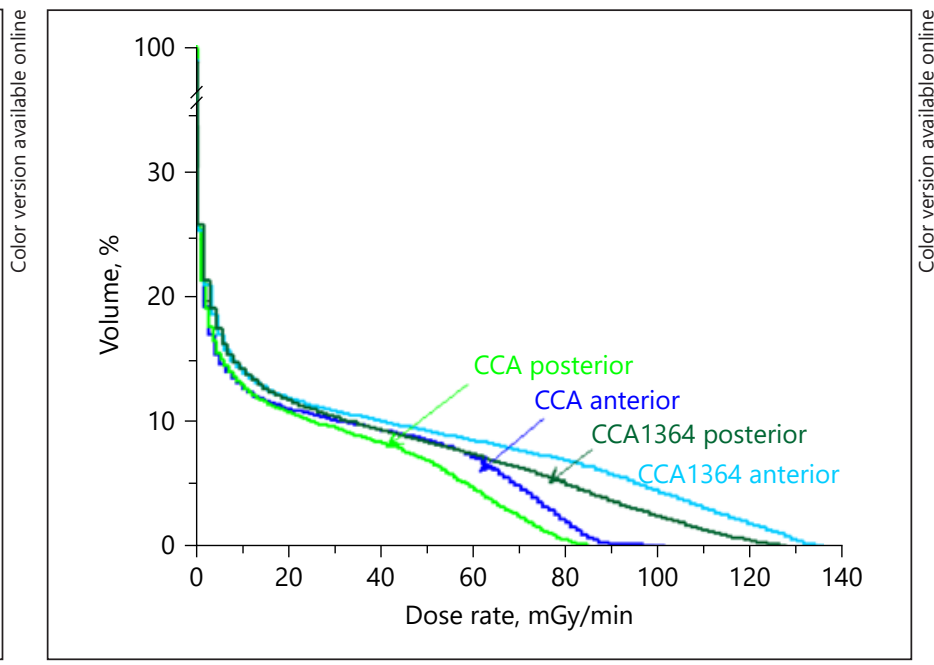

Fig. 2. Dose-volume histograms for the sclera irradiated by the CCA and the CCA1364 plaques in an anterior and posterior placement.

hot spot is oriented close to the segmented structure being analyzed, while for the distal rotation the contrary holds. In all cases, the bin of the hot spot with the largest activity is placed in the axial plane.

Segmentation of Anatomical Structures in the Eye

The human eye is a complex organ formed by different anatomical structures. To segment the anatomical structures of the eye, 2 methods are used. The volumes corresponding to the sclera, the cornea, and the anterior and posterior chamber are defined by grouping quadric surfaces and then selecting the voxels included within the volumes. For segmenting the eye lens, the papilla, the optic disk, the optic nerve, and the lacrimal gland, the voxels belonging to these volumes are manually identified by their coordinates.

The contour enclosing the eyeball is defined as a sphere of 1.215 $\mathrm{cm}$ of radius centered at $3.825 \times 3.452 \times 2.100 \mathrm{~cm}^{3}$ in a cartesian coordinate system whose origin is the lower left posterior vertex of the tomography scan. The equatorial plane of the eyeball is determined by a plane $15^{\circ}$ above the horizontal CT axis that passes through the center of the eyeball. The contours of the sclera and the cornea are defined by 2 concentric spheres of the outer radius of the eyeball and the inner radius of $1.045 \mathrm{~cm}$. The cornea is the volume of a cap with the outer diameter parallel to the equatorial plane of the eyeball 1.1 $\mathrm{cm}$ across the rim of the external sphere. The rest of the volume contained between the spheres corresponds to the sclera.

The spheres and the plane used to segment these structures define the voxels that belong to them. This implies that a voxel divided by a boundary surface needs to be assigned either to the corresponding structure or to the outside. The inclusion criterion is based on the position of the center of the voxel with respect to the boundary surface. An immediate consequence of this criterion is that the thicknesses of the sclera and the cornea are not constant. Both range from approximately 1.2 to $2.1 \mathrm{~mm}$ depending on the number of voxels contained between the 2 boundary spherical surfaces. The average thickness is in agreement with the default value of $1.5 \mathrm{~mm}$ employed in the code EYEPLAN [42, 43] and gives a safety margin of $0.5 \mathrm{~mm}$. 


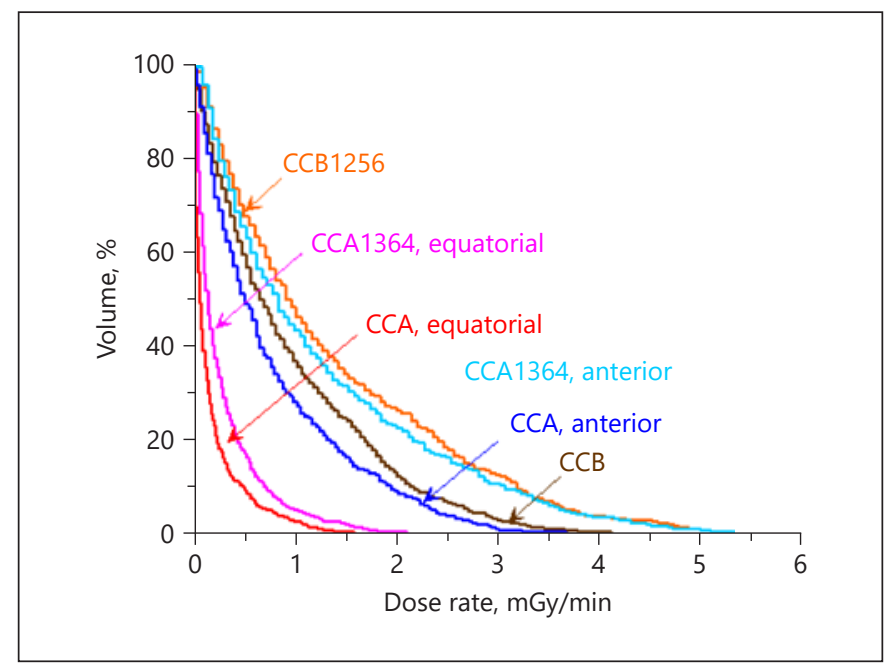

Fig. 3. Dose-volume histograms for the cornea corresponding to plaques in an anterior and equatorial placement. The labels indicate the plaque model and its placement.

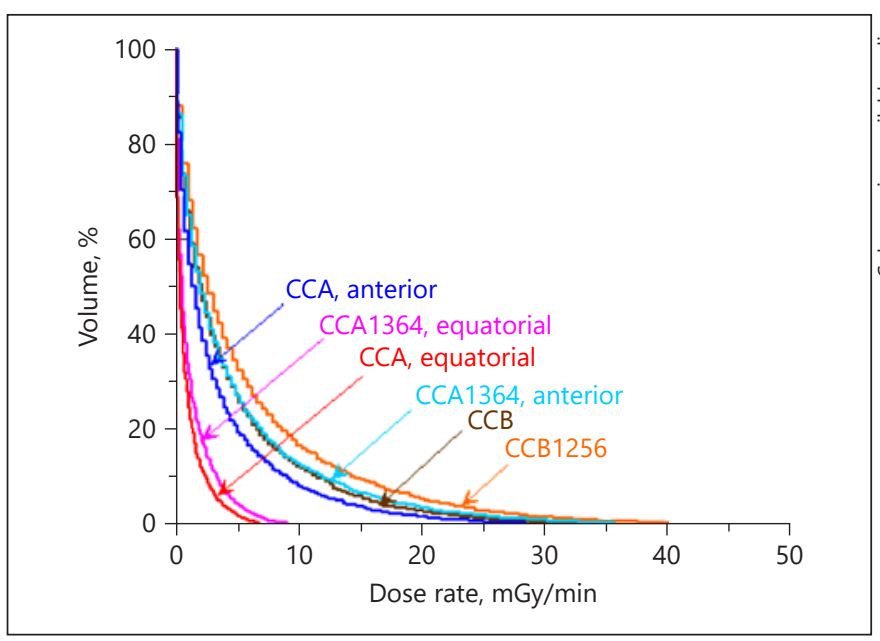

Fig. 5. Dose-volume histograms for the eye lens corresponding to plaques in an anterior and equatorial placement. See caption of Figure 4 for an explanation of the label CCB1256.

\section{Results and Discussion}

Simulated absorbed doses using Monte Carlo methods are expressed in terms of dose per primary particle. These units are converted into $\mathrm{mGy} \mathrm{min}^{-1}$, that is, the dose rate. For this conversion, the activities of the plaques are required. The reached average standard statistical uncertainty of the dose is in all cases $<1 \%$.

The analysis of the considered simulations is based on cumulative dose-volume histograms (DVH) of the afore-

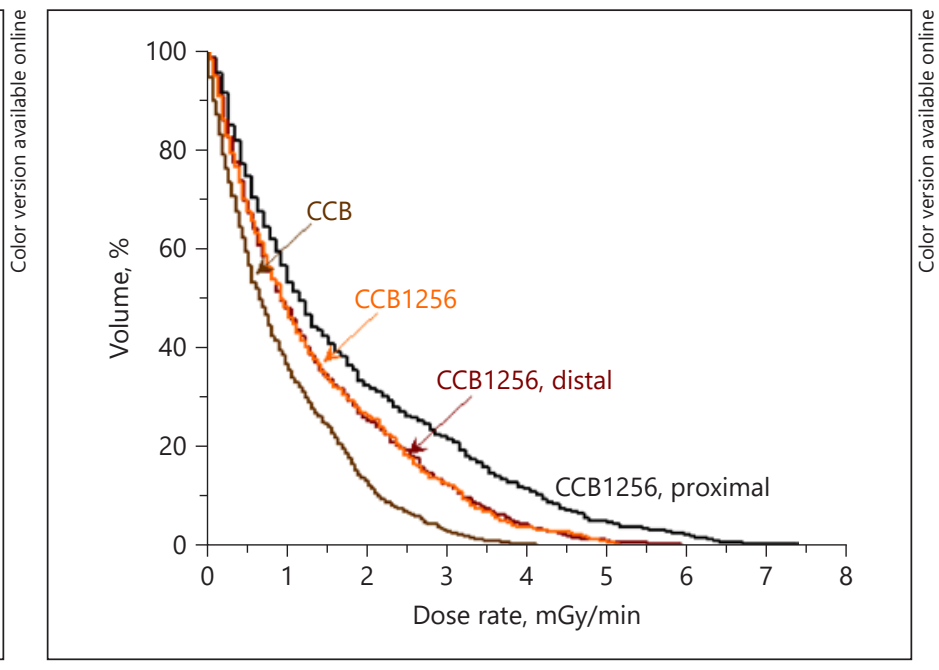

Fig. 4. Dose-volume histograms for the cornea for the CCB and the CCB1256 plaques taking into consideration the hot spot location. The label showing only the plaque model CCB1256 indicates that it is placed in the original orientation.

mentioned anatomical structures. For the sclera, Figure 1 shows DVH corresponding to the equatorial placement, while the anterior and posterior placements are shown in Figure 2.

For the cornea, Figure 3 shows the DVH for anterior and equatorial placements. Notice that the posterior placement is not considered. The maximum absorbed dose rate in the cornea corresponds to the CCA1364 in anterior placement, while the results from the CCB1256 are just $3 \%$ below. The absorbed dose rate using the $\mathrm{CCB}$ is $20 \%$ less than that using the CCB1256. With the CCA plaque in an anterior placement, the absorbed dose rate is $31 \%$ less than that obtained with the CCA1364 in the same placement. The lowest absorbed dose rate of 1.58 $\mathrm{mGy} \mathrm{min}^{-1}$ is achieved for the CCA with the equatorial placement. For the CCA1364 in the same placement, the absorbed dose rate is $33 \%$ higher. Figure 4 shows the comparison of the DVH in the cornea for the CCB and the CCB1256 plaque depending on the location of the hot spot. The maximum dose rate per unit of activity corresponds to the CCB1256 with the proximal rotation. For the CCB and the CCB1256 in the original orientation (hot spot $138^{\circ}$ away from the proximal orientation), the absorbed dose rate is 44 and $30 \%$ lower, respectively. Notice that the effect of the hot spot becomes evident when it is closer to the cornea.

Figure 5 shows the DVH in the eye lens for plaques in an anterior and equatorial placement. As it occurs with the cornea, the posterior location is not considered. The 


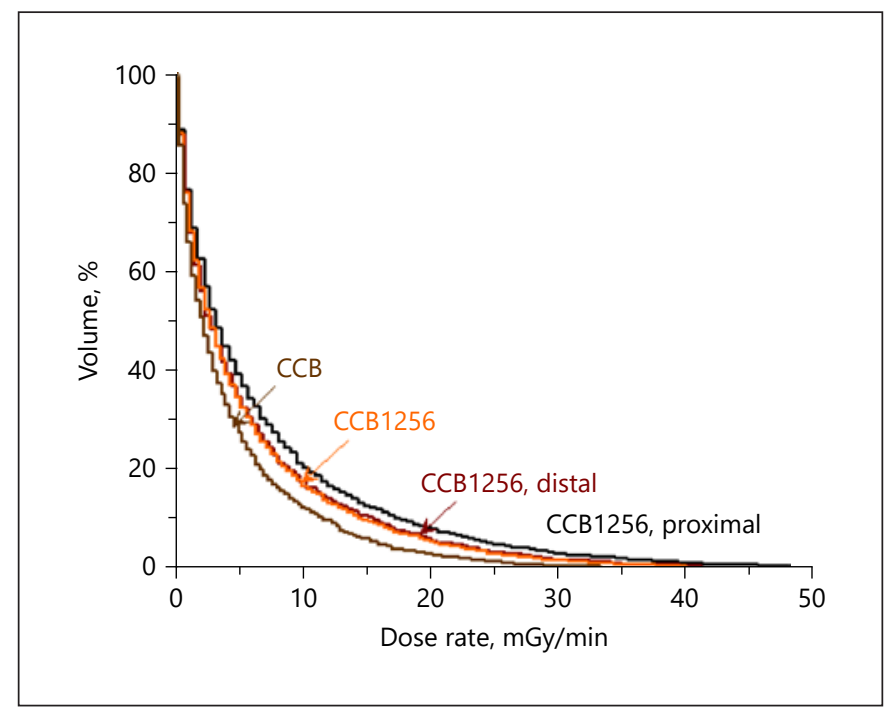

Fig. 6. Dose-volume histograms for the eye lens according to the $\mathrm{CCB}$ and $\mathrm{CCB} 1256$ plaques taking into consideration the hot spot location. See caption of Figure 4 for an explanation of the label CCB1256.

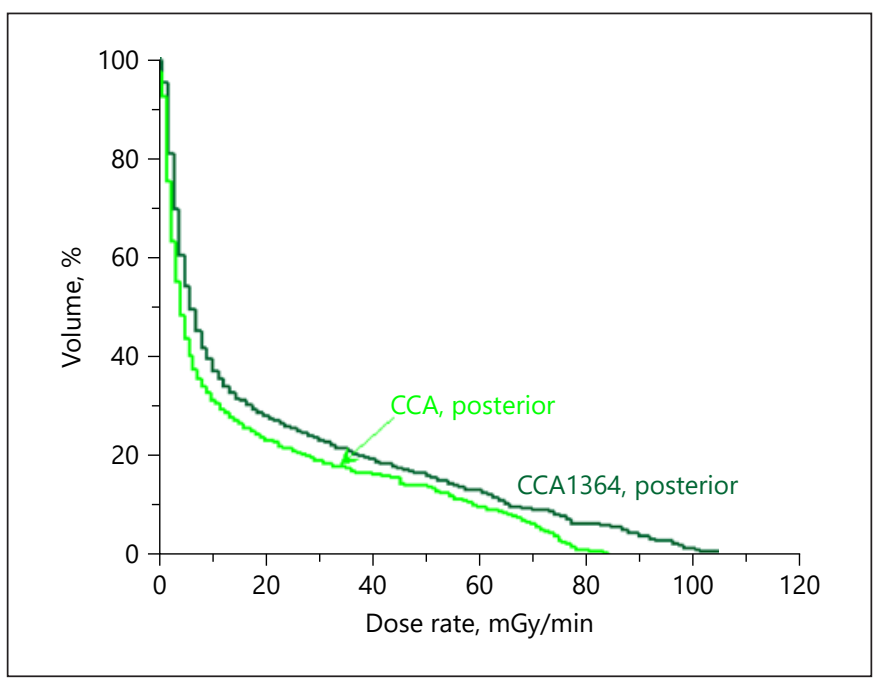

Fig. 8. Dose-volume histograms for the papilla when the CCA and the CCA1364 plaques are placed posteriorly.

CCB1256 plaque yields the maximum absorbed dose rate in the lens. DVH for the CCA1364 and the CCB are similar. For the CCA in an anterior placement, the absorbed dose is $29 \%$ lower than the CCB1256 in original orientation. The absorbed dose for the CCB is $17 \%$ less than the CCB1256 in original orientation. As expected, the equatorial placement for the CCA and the CCA1364 results in the minimum dose with respect to the CCB1256.

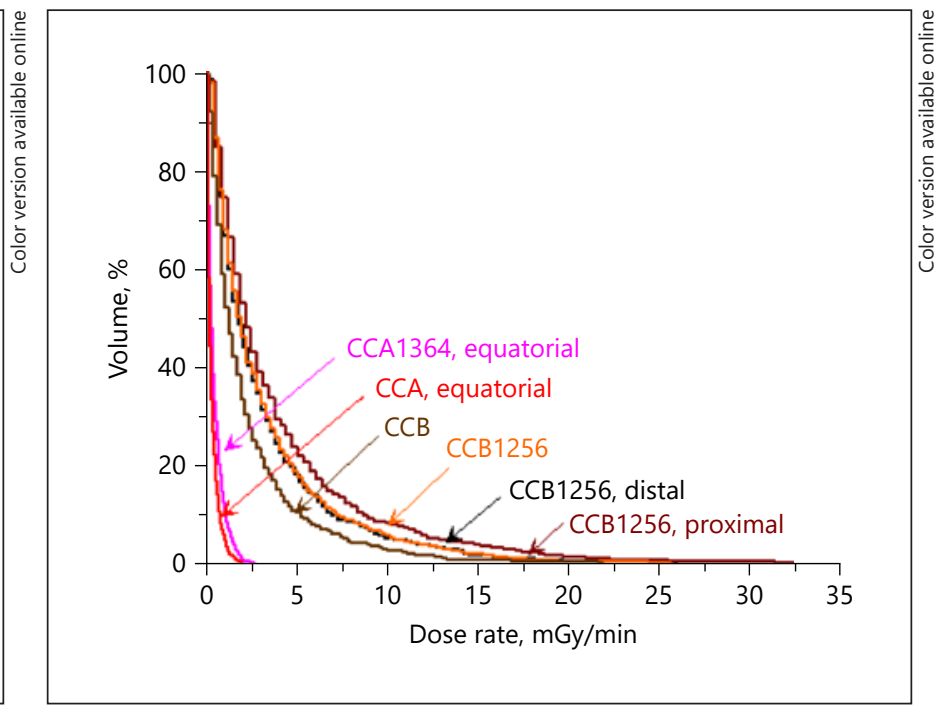

Fig. 7. Dose-volume histograms for the papilla corresponding to plaques in an equatorial placement. The label showing only the plaque model CCB1256 indicates that it is placed in the original orientation.

Figure 6 shows the DVH for the CCB and the CCB1256 plaque with respect to the placement of the hot spot. The maximum absorbed dose rate per unit of activity corresponds to the CCB1256 in the proximal orientation. For the CCB1256 with distal rotation and the CCB, the maximum absorbed dose rates are 17 and $31 \%$ lower than the CCB1256 in proximal rotation, respectively. As it occurs with the cornea, the effect of the hot spot is evident when it is closer to the lens.

Figure 7 shows the DVH of the papilla obtained only by plaques in equatorial placement. The maximum absorbed dose rate in the papilla corresponds to the actual CCB1256 plaque in the proximal rotation. The maximum absorbed dose rate is $48 \%$ higher than in the CCB plaque. For the CCB1256 in the original rotation (hot spot $42^{\circ}$ away from the proximal orientation) and the CCB1256 with a distal rotation, the absorbed dose rates are 22 and $20 \%$ lower, respectively. It is also observed that the CCA1364 and the CCA plaques give the minimum absorbed dose rate per unit of activity. The posterior placement of the plaques implies a $2.4-\mathrm{mm}$ coverage of the papilla. For this reason, the doses delivered by the plaques at this placement are the highest, and they are compared in Figure 8. The maximum absorbed dose rate per unit of activity in posterior placement corresponds to the CCA1364, and it is $25 \%$ higher than the CCA plaque. 


\section{Conclusions}

Heterogeneities on the distribution of the emitter substance in eye plaques and, particularly, the presence of hot spots determine the absorbed dose in the different structures at risk. Rotations of the plaques can reduce or increase the absorbed dose in them.

Dose calculations based on a homogeneous distribution of the emitter substance yield the lowest absorbed dose of the structures analyzed for all plaque placements. Treatment planning based on such calculations may result in an overdosage of the structures at risk. Thus, knowledge of the emitter map of an eye plaque is relevant and needs to be considered when planning a treatment.

\section{Statement of Ethics}

Not applicable. Simulations and experiments presented herein did not include any animal, human, or biological sample.

\section{Conflict of Interest Statement}

The authors have no conflicts of interest to declare.

\section{Funding Sources}

L.B. and B.T. are thankful to the HARMONIC project (Health Effects of Cardiac Fluoroscopy and Modern Radiotherapy in Paediatrics). The HARMONIC project has received funding from the Euratom research and training program 2014-2018 under grant agreement No. 847707. L.B., D.F., and M.E. are thankful to the Deutsche Forschungsgemeinschaft (projects BR 4043/3-1, FL 733/1-1, and EI 869/1-3).

\section{Author Contributions}

F.J.Z. and L.B. conceived the paper and wrote the first manuscript. F.J.Z. ran the simulations. M.E. and D.F. built the device for measuring ruthenium plaques, and measured the plaques reported in this paper. B.T. conceived the required anatomical structures and the orientation of the plaques, and analyzed the DVH. All authors contributed to the manuscript and revised it.

\section{References}

1 Lommatzsch P, Vollmar R. Ein neuer Weg zur konservativen Therapy intraokularer Tumoren mit Betastrahlen (Ruthenium 106) unter Erhaltung der Sehfähigkeit. Klin Monbl Augenheilkd. 1966;148(5):682-99.

2 Lommatzsch P. Treatment of choroidal melanomas with $106 \mathrm{Ru} / 106 \mathrm{Rh}$ beta-ray applicators. Surv Ophthalmol. 1974 Sep-Oct;19(2):85-100.

3 Lommatzsch PK. Results after $\beta$-irradiation (106Ru/106Rh) of choroidal melanomas: 20 years' experience. Br J Ophthalmol. 1986 Nov; 70(11):844-51.

4 Brady LW, Hernández JC. Brachytherapy of choroidal melanomas. Strahlenther Onkol. $1992 \mathrm{Feb} ; 168(2): 61-5$.

5 Tjho-Heslinga RE, Kakebeeke-Kemme HM, Davelaar J, de Vroome H, Bleeker JC, Oosterhuis JA, et al. Results of ruthenium irradiation of uveal melanoma. Radiother Oncol. 1993 Oct;29(1):33-8.

6 Tjho-Heslinga RE, Davelaar J, Kemme HM, de Vroome H, Oosterhuis JA, Bleeker JC, et al. Results of ruthenium irradiation of uveal melanomas: the Dutch experience. Radiother Oncol. 1999 Nov;53(2):133-7.

7 Mourtada F, Koch N, Newhauser W. $106 \mathrm{Ru} / 106 \mathrm{Rh}$ plaque and proton radiotherapy for ocular melanoma: a comparative dosimetric study. Radiat Prot Dosimetry. 2005; 116(1-4 Pt 2):454-60.

8 Schueler AO, Flühs D, Anastassiou G, Jurklies C, Neuhäuser $M$, Schilling $H$, et al. $\beta$-ray brachytherapy with 106Ru plaques for retinoblastoma. Int J Radiat Oncol Biol Phys. 2006 Jul;65(4):1212-21.
9 Mossböck G, Rauscher T, Winkler P, Kapp KS, Langmann G. Impact of dose rate on clinical course in uveal melanoma after brachytherapy with ruthenium-106. Strahlenther Onkol. 2007 Oct;183(10):571-5.

10 Finger PT. Radiation therapy for orbital tumors: concepts, current use, and ophthalmic radiation side effects. Surv Ophthalmol. 2009 Sep-Oct; 54(5):545-68.

11 Russo A, Laguardia M, Damato B. Eccentric ruthenium plaque radiotherapy of posterior choroidal melanoma. Graefes Arch Clin Exp Ophthalmol. 2012 Oct;250(10):1533-40.

12 Simpson ER, Gallie B, Laperrierre N, BeikiArdakani A, Kivelä T, Raivio V, et al.; ABS OOTF Committee. The American Brachytherapy Society consensus guidelines for plaque brachytherapy of uveal melanoma and retinoblastoma. Brachytherapy. 2014 JanFeb;13(1):1-14.

13 Hokkanen J, Heikkonen J, Holmberg P. Theoretical calculations of dose distributions for beta-ray eye applicators. Med Phys. $1997 \mathrm{Feb}$; 24(2):211-3.

14 Davelaar J, Schaling DF, Hennen LA, Broerse JJ. Dosimetry of ruthenium-106 eye applicators. Med Phys. 1992 May-Jun;19(3):691-4.

15 Astrahan MA. A patch source model for treatment planning of ruthenium ophthalmic applicators. Med Phys. 2003 Jun;30(6):1219-28.

16 Soares CG, Vynckier S, Järvinen H, Cross WG, Sipilä P, Flühs D, et al. Dosimetry of beta-ray ophthalmic applicators: comparison of different measurement methods. Med Phys. 2001 Jul;28(7):1373-84.
17 Cross WG, Hokkanen J, Järvinen H, Mourtada F, Sipilä P, Soares CG, et al. Calculation of beta-ray dose distributions from ophthalmic applicators and comparison with measurements in a model eye. Med Phys. 2001 Jul; 28(7):1385-96.

18 Sánchez-Reyes A, Tello JI, Guix B, Salvat F. Monte Carlo calculation of the dose distributions of two 106Ru eye applicators. Radiother Oncol. 1998 Nov;49(2):191-6. Erratum in: Radiother Oncol 1999 Mar;50(3):373.

19 Hermida-López M. Calculation of dose distributions for $12106 \mathrm{Ru} / 106 \mathrm{Rh}$ ophthalmic applicator models with the PENELOPE Monte Carlo code. Med Phys. 2013 Oct;40(10): 101705. Erratum in: Med Phys. 2016 Feb; 43(2): 1020.

20 Barbosa NA, Ribeiro da Rosa LA, de Menezes AF, Reis J, Facure A, Braz D. Assessment of ocular beta radiation dose distribution due to $106 \mathrm{Ru} / 106 \mathrm{Rh}$ brachytherapy applicators using MCNPX Monte Carlo code. Int J Cancer Ther Oncol. 2014;2(3):02038

21 Chetty IJ, Curran B, Cygler JE, DeMarco JJ, Ezzell G, Faddegon BA, et al. Report of the AAPM Task Group No. 105: issues associated with clinical implementation of Monte Carlobased photon and electron external beam treatment planning. Med Phys. 2007 Dec; 34(12):4818-53.

22 Fernández-Varea JM, Carrasco P, Panettieri V, Brualla L. Monte Carlo based water/medium stopping-power ratios for various ICRP and ICRU tissues. Phys Med Biol. 2007 Nov; 52(21):6475-83. 
23 Reynaert N, Van der Marck SC, Schaart DR, Van der Zee W, Van Vliet-Vroegindeweij C, Tomsej M, et al. Monte Carlo treatment planning for photon and electron beams. Radiat Phys Chem. 2007;76(4):643-86.

24 Das IJ, Ding GX, Ahnesjö A. Small fields: nonequilibrium radiation dosimetry. Med Phys. 2008 Jan;35(1):206-15.

25 Jager MJ, Desjardins L, Kivelä T, Damato B, editors. Current concepts in uveal melanoma. Basel: Karger; 2012.

26 Nag S, Quivey JM, Earle JD, Followill D, Fontanesi J, Finger PT; American Brachytherapy Society. The American Brachytherapy Society recommendations for brachytherapy of uveal melanomas. Int J Radiat Oncol Biol Phys. 2003 Jun;56(2):544-55.

27 Bergman L, Nilsson B, Lundell G, Lundell M, Seregard S. Ruthenium brachytherapy for uveal melanoma, 1979-2003: survival and functional outcomes in the Swedish population. Ophthalmology. 2005 May;112(5):83440.

28 Brualla L, Sempau J, Zaragoza FJ, Wittig A, Sauerwein W. Accurate estimation of dose distributions inside an eye irradiated with 106Ru plaques. Strahlenther Onkol. 2013 Jan; 189(1):68-73.

29 Zaragoza FJ, Eichmann M, Flühs D, Sauerwein W, Brualla L. Monte Carlo estimation of absorbed dose distributions obtained from heterogeneous 106Ru eye plaques. Ocul Oncol Pathol. 2017 Sep;3(3):204-9.
30 Zaragoza FJ, Eichmann M, Flühs D, Wittig A, Sauerwein W, Brualla L. Monte Carlo simulation of the treatment of uveal melanoma using measured heterogeneous $106 \mathrm{Ru}$ plaques. Ocul Oncol Pathol. 2019 Jun;5(4):276-83.

31 Council Directive. 2013/59/Euratom of 5 December 2013 laying down basic safety standards for protection against the dangers arising from exposure to ionizing radiation and repealing Directives 89/618/Euratom, 90/641/ Euratom, 96/29/Euratom, 97/43/Euratom and 2003/122/Euratom. OJ. Available from: https://eur-lex.europa.eu/eli/dir/2013/59/oj.

32 Eichmann M, Flühs D, Spaan B. Development of a high precision dosimetry system for the measurement of surface dose rate distribution for eye applicators. Med Phys. 2009 Oct; 36(10):4634-43.

33 Salvat F, Fernández-Varea JM, Sempau J. PENELOPE-2008: A code system for Monte Carlo simulation of electron and photon transport. OECD; 2009. Available from: https://www.oecd-nea.org/science/pubs/ 2009/nea6416-penelope.pdf.

34 Sempau J, Acosta E, Baró J, Fernández-Varea JM, Salvat F. An algorithm for Monte Carlo simulation of coupled electron-photon transport. Nucl Instrum Meth B. 1997;132(3):377-90.

35 Brualla L, Sempau J, Sauerwein W. Comment on Monte Carlo calculation of the dose distributions of two 106Ru eye applicators [Radiother Oncol 49 (1998) 191-196]. Radiother Oncol. 2012;104(2):267-8.
36 Sempau J, Badal A, Brualla L. A PENELOPEbased system for the automated Monte Carlo simulation of clinacs and voxelized geometries-application to far-from-axis fields. Med Phys. 2011 Nov;38(11):5887-95.

37 García-Toraño E, Grau Malonda A. EFFY, a new program to compute the counting efficiency of beta particles in liquid scintillators. Comput Phys Commun. 1985;36(3):307-12.

38 Atchison DA, Jones CE, Schmid KL, Pritchard $\mathrm{N}$, Pope JM, Strugnell WE, et al. Eye shape in emmetropia and myopia. Invest Ophthalmol Vis Sci. 2004 Oct;45(10):3380-6.

39 Brualla L, Zaragoza FJ, Sauerwein W. Monte Carlo simulation of the treatment of eye tumors with 106Ru plaques: a study on maximum tumor height and eccentric placement. Ocul Oncol Pathol. 2014 Oct;1(1):2-12.

40 Brualla L, Palanco-Zamora R, Steuhl KP, Bornfeld N, Sauerwein W. Monte Carlo simulations applied to conjunctival lymphoma radiotherapy treatment. Strahlenther Onkol. 2011 Aug; 187(8):492-8.

41 Brualla L, Zaragoza FJ, Sempau J, Wittig A, Sauerwein W. Electron irradiation of conjunctival lymphoma-monte Carlo simulation of the minute dose distribution and technique optimization. Int J Radiat Oncol Biol Phys. 2012 Jul;83(4):1330-7.

42 Goitein M, Miller T. Planning proton therapy of the eye. Med Phys. 1983 May-Jun;10(3): 275-83.

43 Sheen M. Eyeplan user manual v 3.01. Clatterbridge: Douglas Cyclotron Laboratory; 2001. 